\title{
Design of Sliding Rope Protection Algorithm for Mine Hoist in Iron Mine
}

\author{
Jinyang Xia ${ }^{1}$, Yanping Wang, ${ }^{2, *}$ and Linlin Shao ${ }^{3}$ \\ ${ }^{1}$ Beijing Institute of Fashion Technology, School of Information Engineering, China \\ ${ }^{2}$ Beijing Institute of Fashion Technology, School of Information Engineering, China \\ ${ }^{3}$ Beijing Institute of Fashion Technology School of art and design, China \\ Funding: NHFZ2016010 Promote the development of colleges and Universities \\ *Correspondence author
}

\begin{abstract}
Rope protection is the protection function of large mineral lifting equipment. At present, most of the iron ore hoist sliding rope protection is the speed difference detection algorithm, and it is able to determine whether or not the hoisting machine system has a sliding rope fault, which can give the automatic emergency stop protection. In this paper, a new sliding rope protection algorithm is proposed. This design works with measuring the pulse offset by comparing the difference between the running pulse value of the roller and the running pulse value of the main control system in real time. It determines whether or not the hoisting device has a sliding rope fault. According to the results of the main control system, making the fault protection action, in order to avoid causing major accidents. And it has been applied to the iron ore hoist.
\end{abstract}

Keywords-mine hoist; sliding rope protection; coded sensor; pulse counter; position deviation

\section{INTRODUCTION}

Ore hoist is the ore from the bottom of the transport to the wellhead equipments. According to different purpose, it can be divided into one type equipment and extraction equipment, called auxiliary shaft hoist and main shaft hoist. In the iron ore project, the main shaft skip belt balance hammer iron ore hoist is designed for Hebei iron and Steel Group, and this machine is produced with drum diameter of 4 meters, 6 rope friction hoist tower installation device.

The roller device of hoist is the driving mechanism, providing with anti-skid pad, pad and rope direct contacting with friction between the skip rope and liner lifting. For a period of time, the liner will continue to wear. It gradually becomes smooth. At this time, when the lifting device is running, the wire rope and the roller between the sliding phenomenon.

This paper adopts sliding rope protection design. With running the position difference operation position detecting roller wheel and the God in the allowed error range, the system can determine whether the hoist rope slip fault.

\section{MAin Hoist Rope SLiding CAUSEs Problems}

The main shaft of the project adopts 6 ropes friction drive. DC transmission mechanism rotates the main shaft drive roller device. Hoisting ropes are respectively rounded drum, wheel and wheel under heaven, as shown in Figure II-1.
If the DC motor $\mathrm{M}$ operates normally, the main driving shaft would transfer torque to the roller device. Then the drum device will rotate with the DC driving motor. At the same time, the cylinder liner will be nested by friction with roller rotary in the rope drum lying on the surface of the device. What is more, the control DC motor reversing can skip the upstream and downstream operation device.

After a period of operation, as the roller device has the friction between wire rope and liner. So, the liner will be removed, resulting in the relative sliding between wire rope and liner, causing position control, speed control and cylinder diameter calculation function failure, in the main control system.

Therefore, in order to eliminate the rope failure, or when the fault occurs, the fault can be timely warned and emergently stops the transport bus. Well, this design is essential.

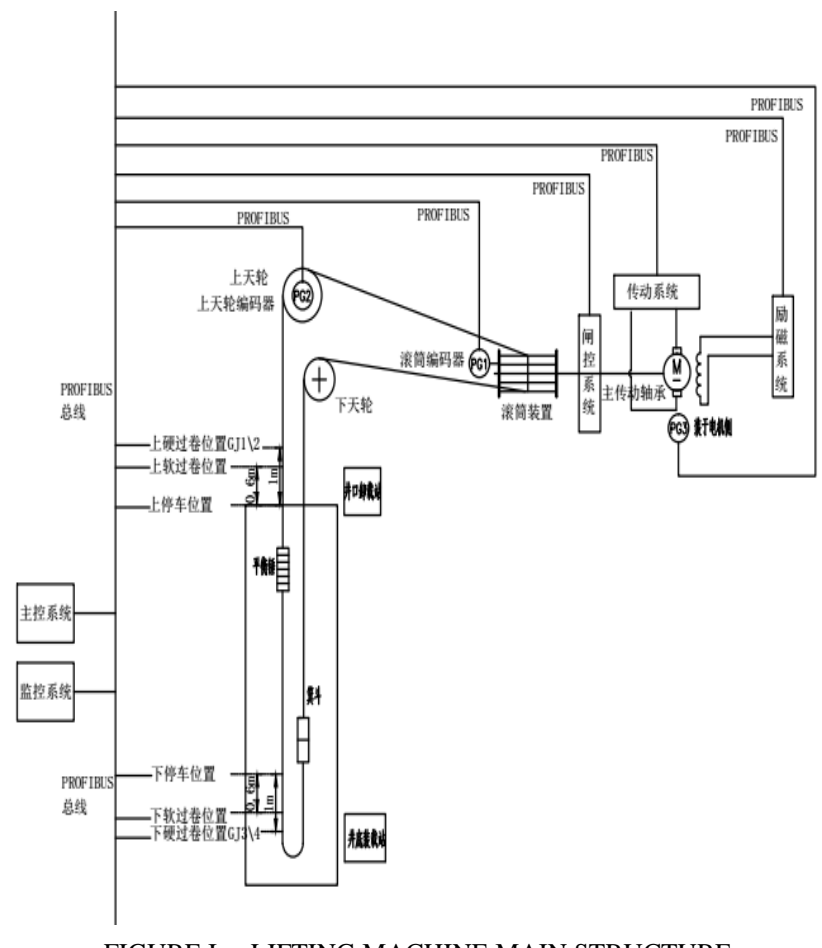

FIGURE I. LIFTING MACHINE MAIN STRUCTURE 


\section{The Hoisting Machine Design Of SLIDING Rope PROTECTION}

Improve the equipment running, installed on the main shaft of the roller PG1 encoding sensor and installation and wheel spindle God sensor PG2 respectively encoding memory and pulse counting, pulse count value are assigned to local variables Encoder_Counter1 and Encoder_Counter2, for sliding rope protection detection subroutine main control system.

A. Calculating the Number of Meters Per Pulse in the Drum Unit

$$
H_{-} P_{1}=\frac{\pi * D}{4 * 4096}(\text { III- } 1)
$$

H_P1: Per pulse meter;

$\mathrm{D}$ : roller diameter $\mathrm{D}=4 \mathrm{~m}$;

The diameter of the roller device is $4.0 \mathrm{~m}$, and the drum of perimeter can be worked out, with the circumference of the rotation of a week than the rotation of the pulse count, that can be obtained in the cylinder of the number of meters per pulse H_P1, as shown in III-1.

B. Calculate the Number of Pulses Per Pulse

$$
H_{-} P_{2}=\frac{\pi * D / 2}{4 * 4096}(\mathrm{III})
$$

H_P2: Per pulse meter;

$\mathrm{D} / 2$ : God wheel diameter $\mathrm{D} / 2=2 \mathrm{~m}$;

Type III-1 can be obtained by the number of meters per pulse on the sheave H_P2.

C. Lifting Machine Position Calculated According to the Roller Device

M_Position1=Encoder_Counter1×H_P1 (III)

M_Position2=Encoder_Counter2×H_P2 (III) PG1;

Encoder_Counter1:The pulse count value of coded sensor PG2;

Encoder_Counter2:The pulse count value of coded sensor

WithIII-3 and III-4, the position value of the elevator is calculated.M_Position1 and M_Position2.

D. Measuring the Deviation of the Position of the Roller and the Position of the Sky Wheel

M_Position_Dev=|M_Position_1-M_Position_2 (III)

The drum position measurements make the difference operation and God wheel position measurements, and get the absolute value, which can calculate the hoist position deviation of M_Position_Dev. When the rope slides, it can figure out rope sliding distance.
E. Whether the Distance of the Sliding Rope of the Hoist is More than the Allowable Range of the Sliding Rope

During the normal operation of lifting equipment, there is an inevitable phenomenon of rope between the wire rope and the shaft. Because of its relatively sliding distance is small, so it can be ignored. According to the relevant provisions of the national coal mine design code and coal mine safety regulations, this paper will allow the distance of the sliding rope to be designed as $0.5 \mathrm{~m}$ range. When the hoist rope fault occurs:

If M_Position_Dev $\leqslant 0.5 \mathrm{~m}$, the lifting equipment is considered as the normal operation, There is no sliding rope fault;

If M_Position_Dev $>0.5 \mathrm{~m}$, the system exists sliding rope lifting equipment fault. Meanwhile, the main control system of hydraulic pump off safety circuits, shutting off the circuits power. Hydraulic mechanism will push the brake parking brake, and a sliding rope fault emergency alarm will be activated;

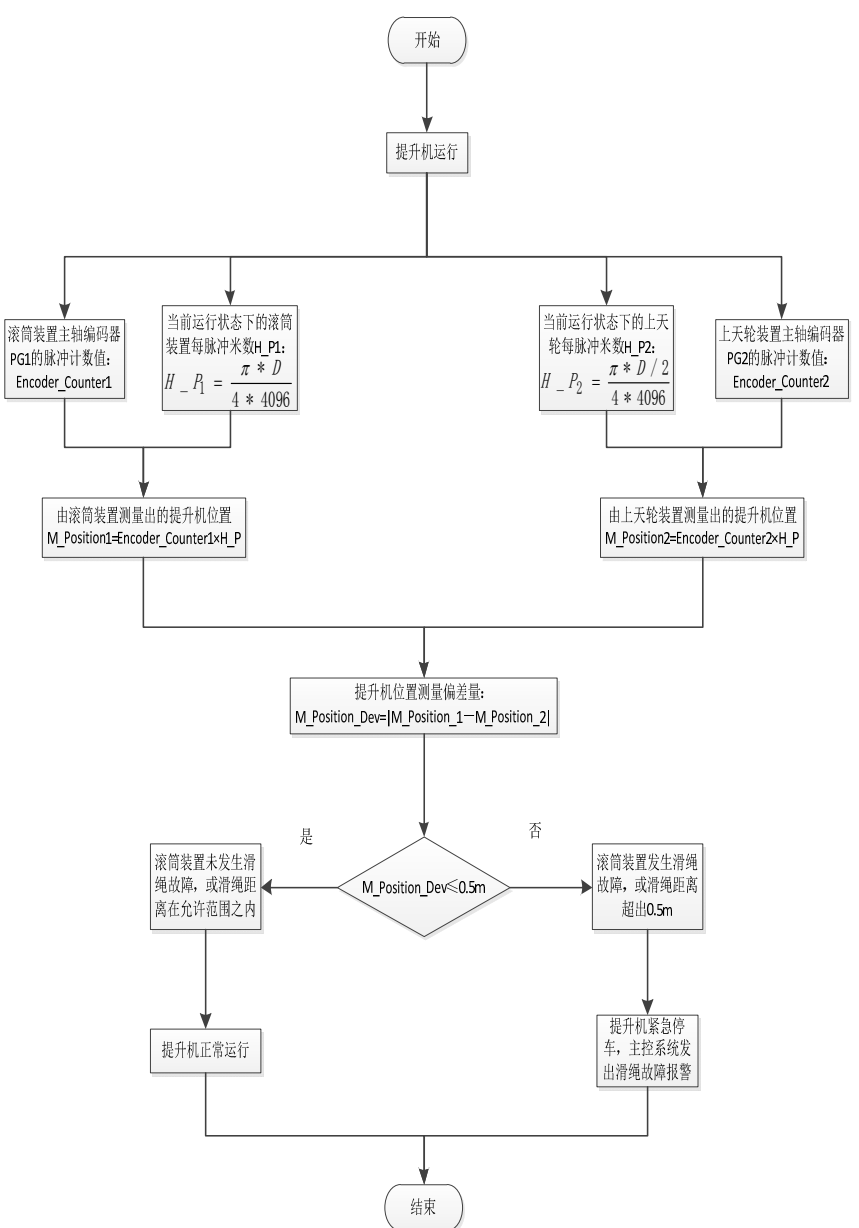

FIGURE III. DESIGN OF PROTECTIVE FUNCTION OF SLIDING ROPE

According to the above sliding rope protection design ideas, it can carry on the sliding rope protection function design, as shown in Figure III. 


\section{Program Design OF SLIDING RoPe HoIsting MACHINE PROTECTION}

In order to use the program repeatability, the PLC programming method of object-oriented program is used to design the sliding rope protection program. And the subroutine is packaged, which can directly be called in other programs.

According to the idea of the sliding rope fault, the design of the function of the rope protection function is shown in Figure IV:

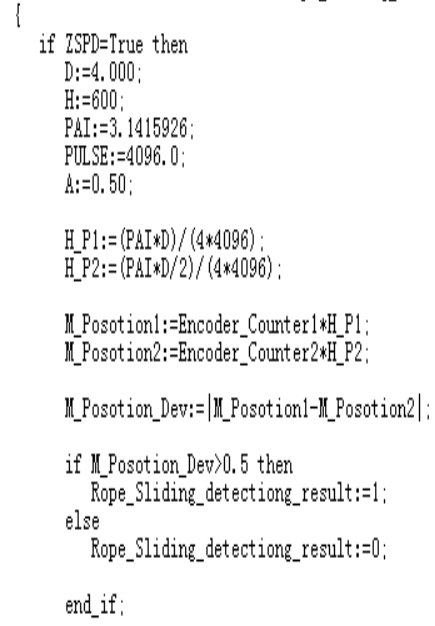

\section{ACKNOWLEDGMENT}

The protection function of sliding rope can effectively prevent the over winding fault and the fault of the car during the operation of th guarantee the accuracy and reliability of the main control system of position control, make the machine more stable and improve traffic safety.

This design by the iron main background of the project, can be applied to the lifting mechanism of sliding rope detection. Compared with the speed of the sliding rope detection method, position detection algorithm is more intuitive and easy to control, and position measurement can be measured easily.

Therefore, position detection algorithm of sliding rope protection is more practical, simple and easy to achieve. This design proposes algorithm for determining the position of the sliding rope protection to facilitate other projects .

e hoist, which plays an important role in the normal operation of the lifting equipment. Through the design of sliding rope protection function, the lifting equipment can accurately stop at the horizontal position, also can ensure the skip synchronization operation in synchronous position. It will

\section{REFERENCE}

[1] Design parameters of electric control system of Hebei iron and Steel Group, Feng Lai, 2015-9, Reference page : page1-19;
[2] Modern digital elevator control system, Jianmin Ma Zengyu Zhao .Publisher: China University of Mining and Technology press (Xuzhou), publication year: August 2002;

[3] "In the" iron main drawings , Feng Xia. In the internal data near iron ore project, November 2015;

[4] "The hoisting electric control system", Jinyang Xia. Master degree thesis of Beijing Institute Of Fashion Technology.2016 August; 